\title{
Neptunium Immobilization and Recovery Using Phase Separated Glasses .
}

by

T. F. Meaker

Westinghouse Savannah River Company

Savannah River Site

Aiken, South Carolina 29808

This paper was prepared in connection with work done under the above contract number with the U.S. Department of Energy. By acceptance of this paper, the publisher and/or recipient acknowledges the U.S. Government's right to retain a nonexclusive, royalty-free license in and to any copyright covering this paper, along with the right to reproduce and to authorize others to reproduce all or part of the copyrighted paper. 


\section{DISCLAIMER}

This report was prepared as an account of work sponsored by an agency of the United States Government. Neither the United States Government nor any agency thereof, nor any of their employees, makes any warranty, express or implied, or assumes any legal liability or responsibility for the accuracy, completeness, or usefulness of any information, apparatus, product, or process disclosed, or represents that its use would not infringe privately owned rights. Reference herein to any specific commercial product, process, or service by trade name, trademark, manufacturer, or otherwise does not necessarily constitute or imply its endorsement, recommendation, or favoring by the United States Government or any agency thereof. The views and opinions of authors expressed herein do not necessarily state or reflect those of the United States Government or any agency thereof.

This report has been reproduced directly from the best available copy.

Available to DOE and DOE contractors from the Office of Scientific and Technical Information, P.O. Box 62, Oak Ridge, TN 37831; prices available from (615) 576-8401.

Available to the public from the National Technical Information Service, U.S. Department of Commerce; 5285 Port Royal Road, Springfield, VA 22161. 


\section{DISCLAIMIER}

Portions of this document may be illegible in electronic image products. Images are produced from the best available original document. 
WESTINGHOUSE SAVANNAH RIVER COMPANY

SAVANNAH RIVER TECHNOLOGY CENTER

WSRC-TR-96-0380 Rev. 1

Keywords: Neptunium surrogate, dissolution, surface area.

January 16, 1997

To: Distribution

From: T.F. Meaker, 773-A

NEPTUNIUM IMMOBILIZATION AND RECOVERY USING PHASE SEPARATED GLASSES

CC: E.W. HOLTZSCHEITER, 773-A

J.M. PAREIZS, 773-A

N.E. BIBLER, 773-A

D.K. PEELER, 773-A

M.J. PLODINEC, 773-A

E.F. DUHN, 773-A

D.A. CROWLEY, 773-43A

T.Y. BAXTER, 773-A

STI (4) 


\section{Summary}

A phase separated (amorphous) glass has been developed which allows very effecient recovery of +4 valence actinides. The total amount of crystal formation in a heat treated vycor-type glass can be controlled with time, temperature and loading. Heat treatments at lower temperatures and for less time inhibit crystal formation while still allowing significant phase separation. If the Thorium loading exceeds 10 weight percent oxide, crystal formation during heat treatment may not be avoided. The total amount of crystal growth has a direct affect on thorium leachability. An increase in crystal formation limits the Th recovery significantly. High thorium loaded glasses ( 15 weight percent) with heat treatments (increased crystal formiation) leach at approxiniately the same rate as non-heat treated glasses.

A phase separated (amorphous) glass has been produced using thorium as a surrogate for neptunium. Two different homogeneous vycor compositions targeting 10 and 15 weight percent thorium oxide have been processed, heat treated and leached with concentrated nitric acid at $110^{\circ} \mathrm{C}$. Thorium recovery rates have been shown to be considerably better when the glass has been heat treated inducing phase separation that is relatively crystal free. Non-heat treated and crystalline (due to heat treatment) glasses have similar Th recovery rates with respct to surface area. Phase separated amorphous samples were found to have significantly higher thorium concentrations in the leachate compared to non-heat treated and crystalline glasses for all mesh sizes. All glasses had increased thorium concentration in the leachate as surface area increased.

Thorium leach rates of greater than 90 percent have been achieved by contacting a large mesh size, heat treated glass with nitric acid at $110^{\circ} \mathrm{C}$ for 4 hours. The heat treatment was for 7 hours at $650^{\circ} \mathrm{C}$. The glass contained very few crystals after the heat treatment. Thorium leach rates for a slightly more crystallized sample was $\sim 20$ percent less. Non-heat treated glasses show $\sim 40$ percent less recovery compared to the sample with very few crystals.

Non-heat treated glasses exhibited very low silica releases. Typical levels are at or below 5 ppm of silica dissolved in solution for large mesh sizes and greater than $15 \mathrm{ppm}$ for small mesh sizes. Large glass fragments of phase separated (amorphous) samples had a silica release also below $5 \mathrm{ppm}$. However, glasses containing amorphous phase separation and crystalline phases did show a ten fold (10X) increase in total silica dissolved as the surface area increased.

\section{Introduction}

The Savannah River Site (SRS) presently neptunium stored in H-canyon. Oak Ridge National Laboratory (ORNL) has a possible need in the future for the neptunium. Neptunium is used as target material in the production of $\mathrm{Pu}-238$. $\mathrm{Pu}-238$ may be needed as an energy source for future NASA missions. A glass composition designed for the easy recovery of neptunium may be necessary to transport it to ORNL. ORNL requires easy recovery of the $\mathrm{Np}-237$ in order to process it efficiently. Tedious chemical separations (i.e. from lanthanides) would adversely impact production schedules. Furthermore, RCRA materials should not be part of the glass composition to avoid a mixed waste after separation processes. Also, high silica concentrations in the feed could lead to precipitation causing a pressure build-up during separation techniques resulting in dangerous operating conditions. 
To meet these objectives, a glass composition resembling a vycor ${ }^{\circledR}$ composition used in industry is being evaluated as a possible solution to the transportation/separation problems. This glass composition would contain only $\mathrm{SiO}_{2}, \mathrm{Na}_{2} \mathrm{O}, \mathrm{B}_{2} \mathrm{O}_{3}$ and $\mathrm{NpO}_{2}$. In industry, the glass is heat treated causing a glass-in-glass phase separation between the silica and sodaborate phases. Leaching the glass in concentrated nitric acid removes the soda-borate phase leaving a high silica glass in tact [1]. It has been shown that transition metals in the glass matrix will be separate from the silica phase and remain in the soda-borate phase [2]. Us: horium as a surrogate for neptunium, this glass composition is being evaluated for ear $N$ p recovery while not introducing silica into the leachate and subsequent separation pi $\wedge$ sses.

\section{Exp̉erimental}

Glass Fabrication

Glass compositions were batched with reagent chemicals in $100 \mathrm{~mL}$ platinum crucibles. Table 1 shows the two glass compositions used in this study. The melt was ramped to temperature $\left(1250^{\circ} \mathrm{C}\right.$ ) and held for approximately four hours. The crucible was prriodically removed from the furnace and stirred with a platinum stir bar. The glass was cast into graphite molds and annealed at $450^{\circ} \mathrm{C}$ for approximately one hour.

T.ahle 1. Composition of two vycor glasses with thorium loading.

Oxide

$\mathrm{SiO} 2$

$\mathrm{B} 2 \mathrm{O} 3$

$\mathrm{Na} 2 \mathrm{O}$

$\mathrm{ThO} 2$ $\underline{\text { Mid10 }}$

55.1

10.0

\section{TG15}

55.6

22.7

6.7

15.0

I icat Treatments

1

The processed glass was fractured with a hammer. Small portions ( $\sim 5$ grams) of the glass $\checkmark$. re put in $30 \mathrm{~mL}$ platinum crucibles and placed in a preheated muffle furnace to induce p es separation. Temperatures ranged from $500^{\circ}$ to $700^{\circ} \mathrm{C}$ and time was varied from 1 to 2 inurs.

Pnase Separation Characterization

A few small chips of the the glass after different heat treatments were examined with transmission electron microscopy (TEM), X-ray diffraction (XRD) and scanning electron microscopy (SEM). TEM was able to show, in great detail, if the heat treated glass samples had glass-in-glass phase separation and/or crystallization.

\section{Dissolution}

The 5 gram glass sample of a crystalline heat treated glass, phase separated amorphous glass and a non-heat treated glass were ground in a Tekmar grinder and sieved. Six different size fractions of each glass were collected ranging in size between $>40$ mesh [equivalent to $\sim 1620 \mathrm{~mm}^{2}$ surface area] to $<200$ mesh [equivalent to $\sim 21400 \mathrm{~mm}^{2}$ surface area]. Approximately 0.5 grams of each size fraction was contacted for one hour with 10 $\mathrm{mL}$ of concentrated nitric acid at $110^{\circ} \mathrm{C}$ in a sealed teflon vessel in a drying oven.

Another 5 gram sample of the phase separated amorphous glass was ground and sieved collecting only the $>40$ mesh and 40-60 mesh size fractions [SA $=1620$ and $3200 \mathrm{~mm}^{2}$, respectively]. These sizes were contacted with $10 \mathrm{~mL}$ of concentrated nitric acid at $110^{\circ} \mathrm{C}$ for times ranging from 15 minutes to 8 hours. 
After the appropriate time, the samples were removed from the oven. A $5 \mathrm{~mL}$ aliquot was carefully removed from the vessel so as not to remove any of the remaining glass fragments. This was diluted with $15 \mathrm{~mL} \mathrm{DI} \mathrm{water.} \mathrm{The} \mathrm{samples} \mathrm{were} \mathrm{then} \mathrm{analyzed} \mathrm{by}$ inductively coupled plasma emission spectroscopy (ICPES) for $\mathrm{Th}, \mathrm{Si}, \mathrm{Na}$ and $\mathrm{B}$.

\section{Results and Discussion}

Phase Separation Characterization Results

TEM/EDAX was able to identify thorium- and silicon-rich phases and determined if they were amorphous or crystalline in the heat treated glasses. Figures 1 and 4 show the glass samples targeting 10 and 15 weight percent $\mathrm{ThO}_{2}$ with a heat treatment of $650^{\circ} \mathrm{C}$ for 10 hours. These were used in the dissolution experiments that varied the surface area of the sample while time and dilution volume were kept constant. Notice the 10 weight percent sample had a phase separated amorphous structure with large silicon-rich droplets and a continuous (appears as the mottled region) thorium-rich phase. Figures 2 and 3 show the EDAX spectrum for the different regions of figure 1. Other heat treatments resulted in plate-like crystallization throughout the glass sample. In figure 4, amorphous phase separation similar to figure 1 is present as well as crystal formation. Figure 5 shows the EDAX spectrom of one of the crystal forms. Notice that it is also thorium rich (as is the mottled region). Possible explanations include precipitation of $\mathrm{ThO} 2$ or ThSiO4. However, this crystal may be cristabolite formation that has formed with some Th. This has been observed before with HLW glass at Hanford [3].

Figure 1. Phase separated amorphous glass showing silicon rich droplets and a mottled thorium rich phase of a 10 weight percent $\mathrm{ThO}_{2}$ glass heat treated at $650^{\circ} \mathrm{C}$ for 10 hours.

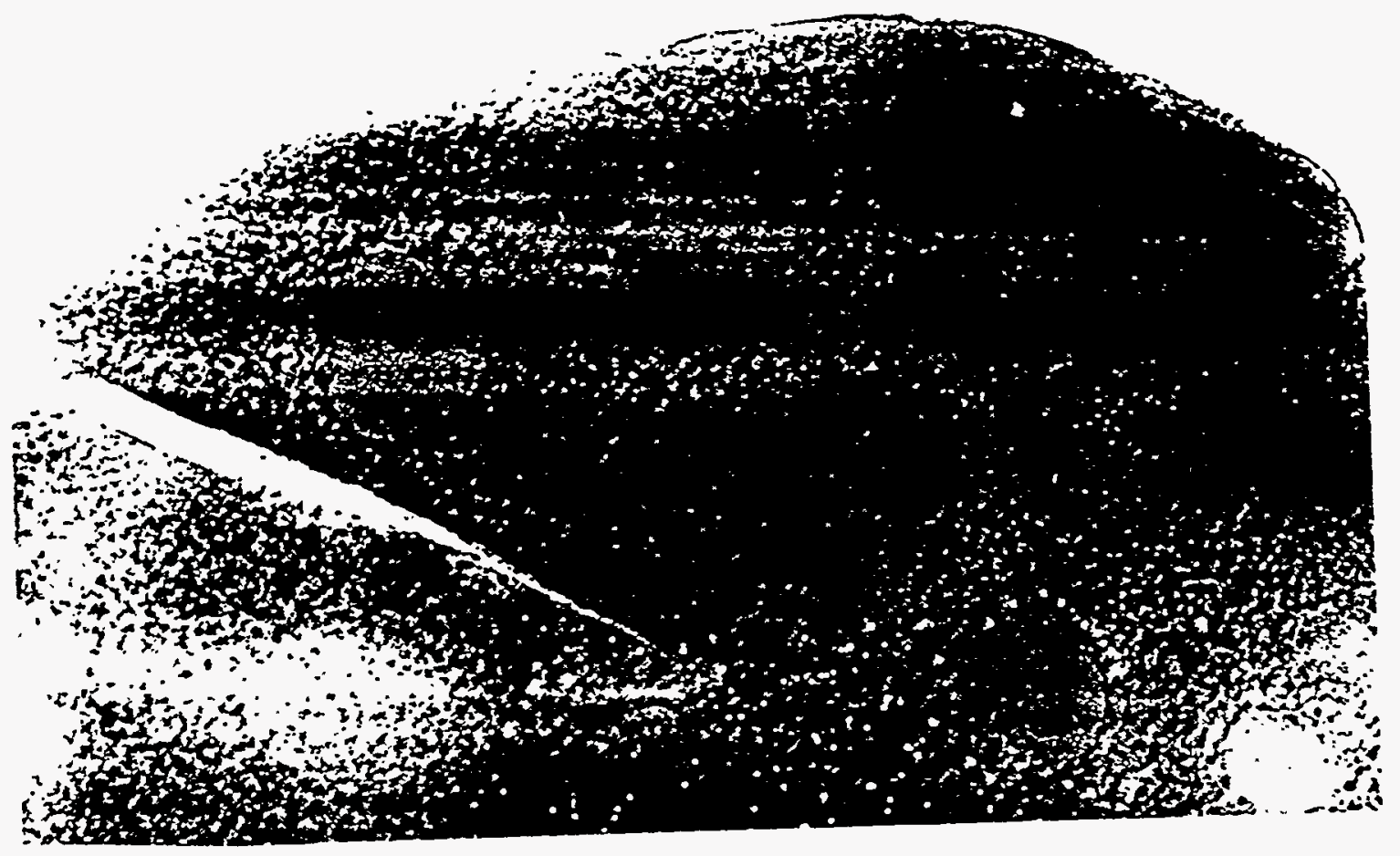


Figure 2. EDAX spectrum of large (clear) droplets showing Si-rich phase.

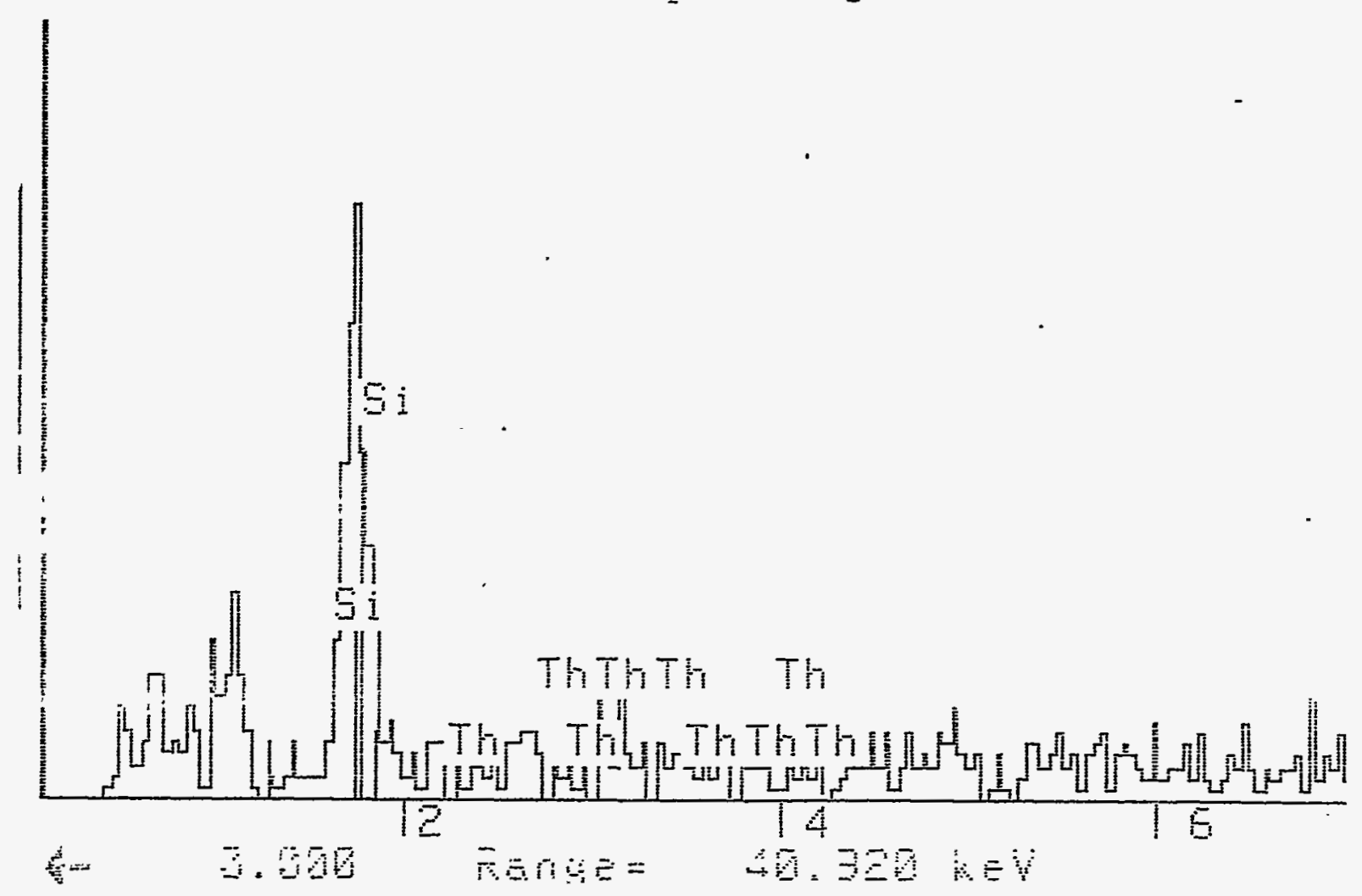

Figure 3. EDAX spectrum of continuous (mottled) region showing Th-rich phase.

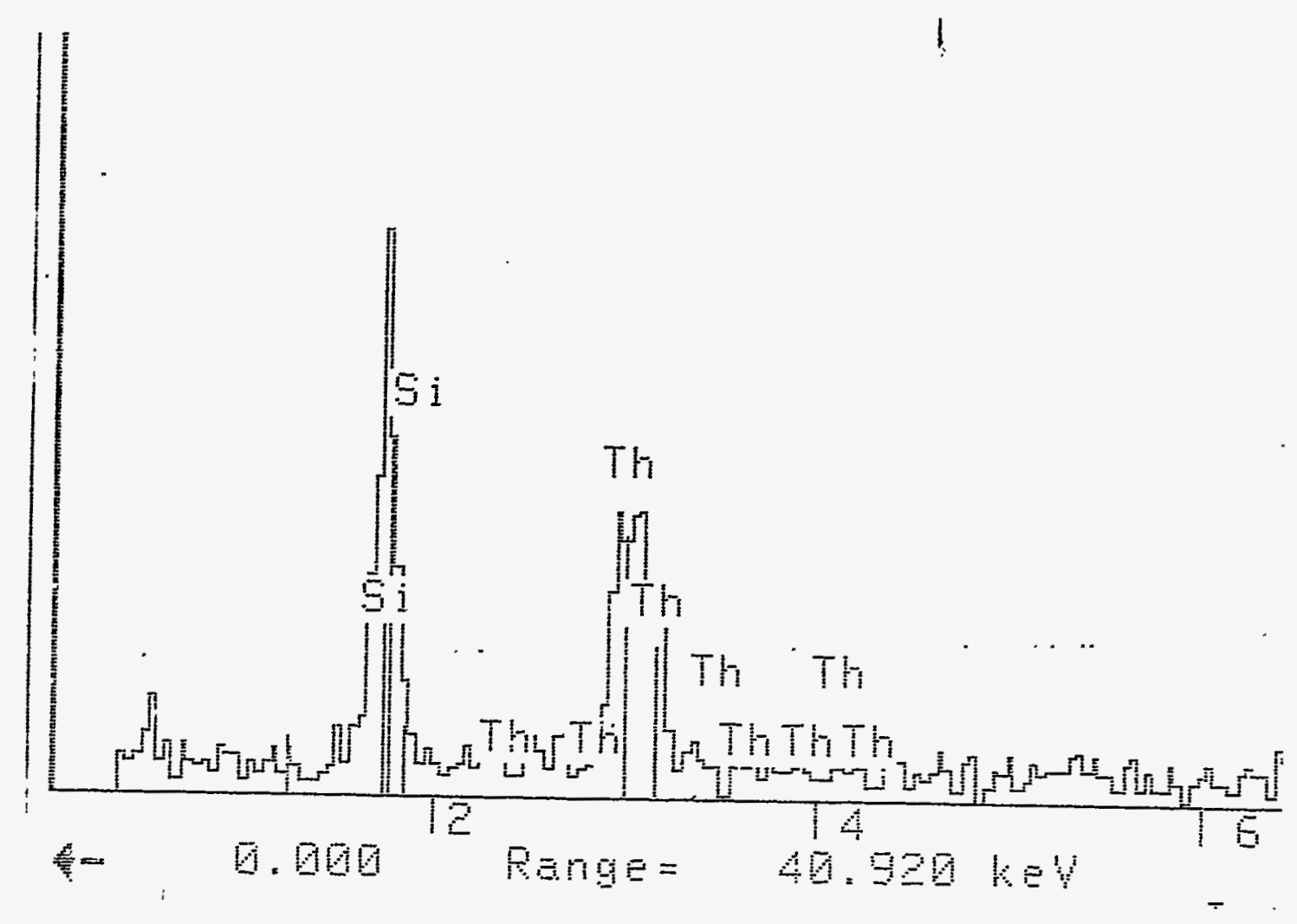


Figure 4. Phase separated glass with crystal formation showing silicon rich droplets, a mottled thorium rich phase and Th-rich crystals of a 15 weight nercent $\mathrm{ThO}_{2}$ glass heat treated at $650^{\circ} \mathrm{C}$ for 10 hours.

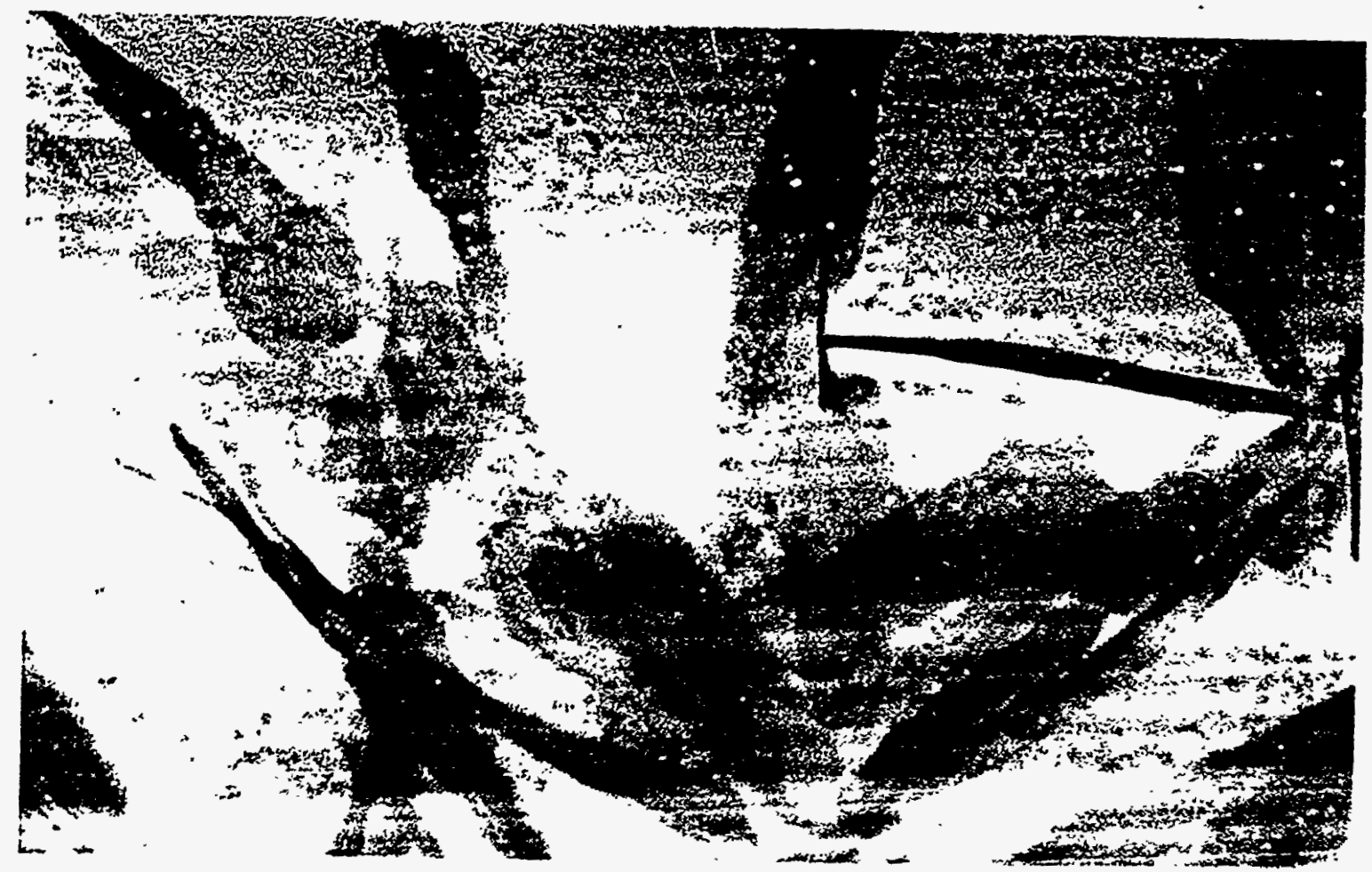

Figure 5. EDAX spectrum of the plate-like crystals seen in figure 4.

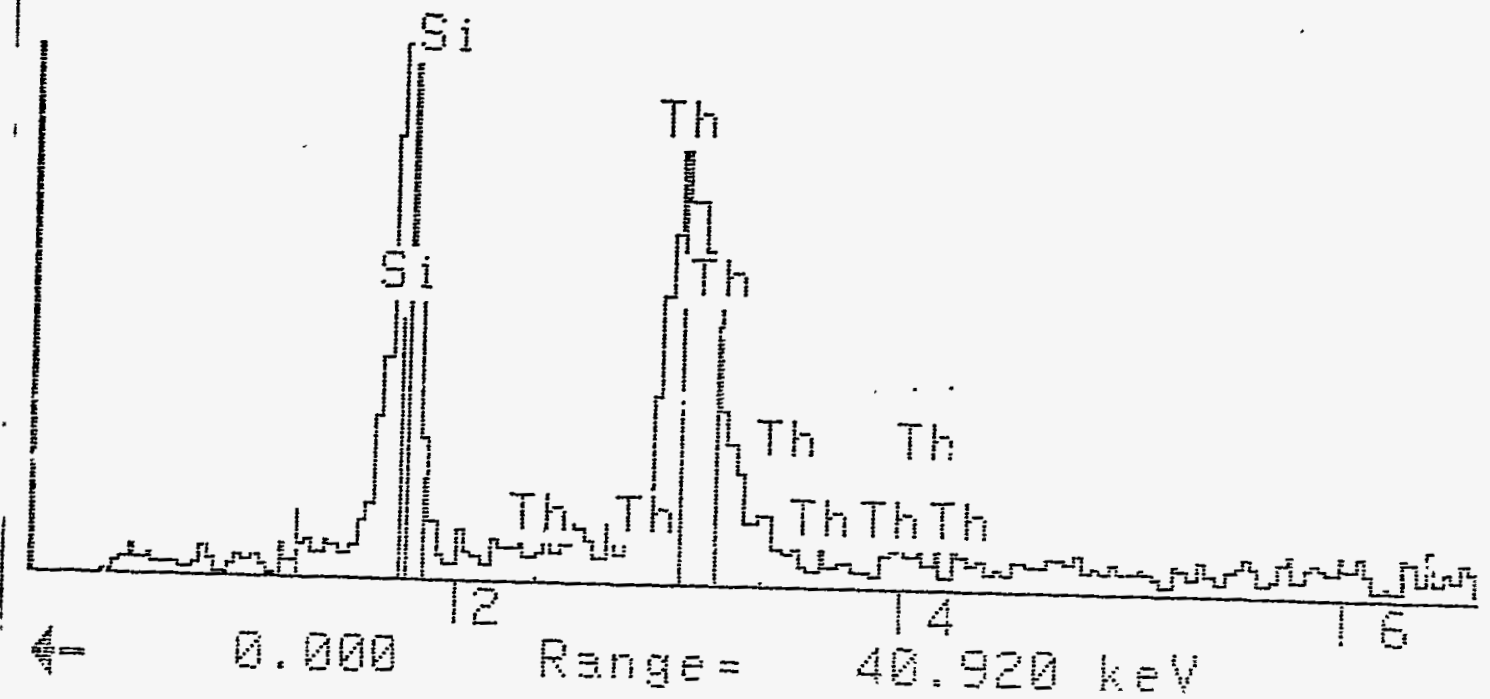


Dissolution Results

Figure 6 shows the recovery rates of all elements of a non-heat treated, amorphous glass. Note $t^{b}$ linear relationship between surface area and percent recovery for all elements. Silicer. lease levels are in the part-per-million range. Figure 7 shows a comparison of thon :ecovery levels of two glasses with 10 and 15 weight percent $\mathrm{ThO}_{2}$ loadings with a heat reatment at $650^{\circ} \mathrm{C}$ for 10 hours (to induce phase separation) and two non-heat treated glasses with the same loadings. The heat treated glass with the lower loading was crystal free (as seen in the above TEM micrographs). It had a Th recovery rate with respect to surface area far exceeding that of the crystallized sample. The crystallized sample had a recu very rate similar to both non-heat treated glasses. Figure 8 shows the silicon release in part;-per-million of the same glasses with respect to surface area is linear. The heat treated glasies show low levels of silica in the leachate from thie larger mesh size fractions. These values are similar to non-heat treated glasses. However, as the particles decrease in size, the ilicon concentration in the leachate increases linearly. This shows that recovery stra' $\cdots$ need to target large particles to maximize recovery of actinide and minimize unu sntea silica.

Fig. Recovery rates of all elements with respect to surface area in a non-heat treated (am, , nous) vycor composition with $\mathrm{ThO}_{2}$ loading.

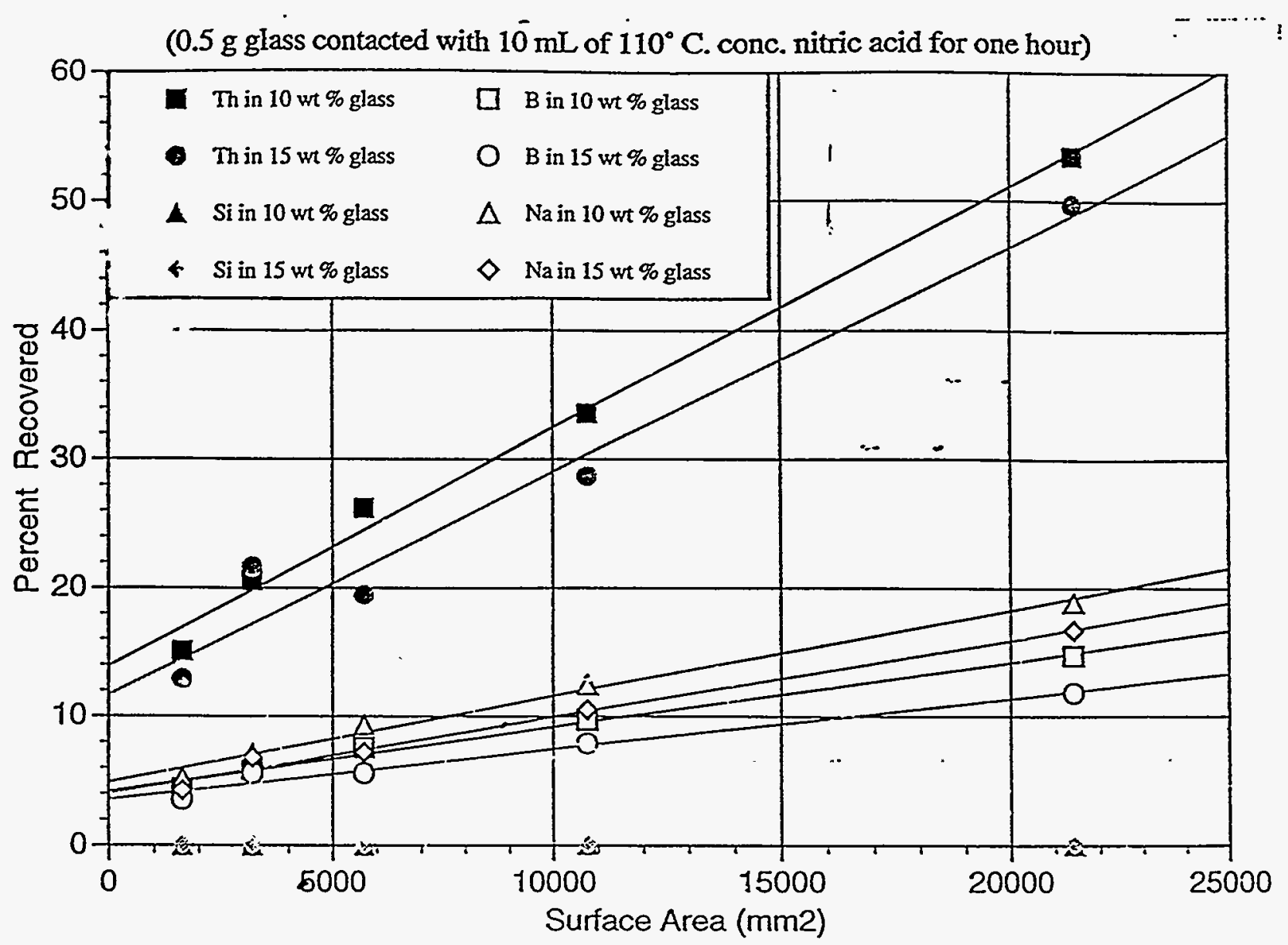


Figure 7. Th recovery rates with respect to surface area of heat treated and non-heat treated glasses with 10 and 15 weight percent $\mathrm{ThO}_{2}$ loadings.

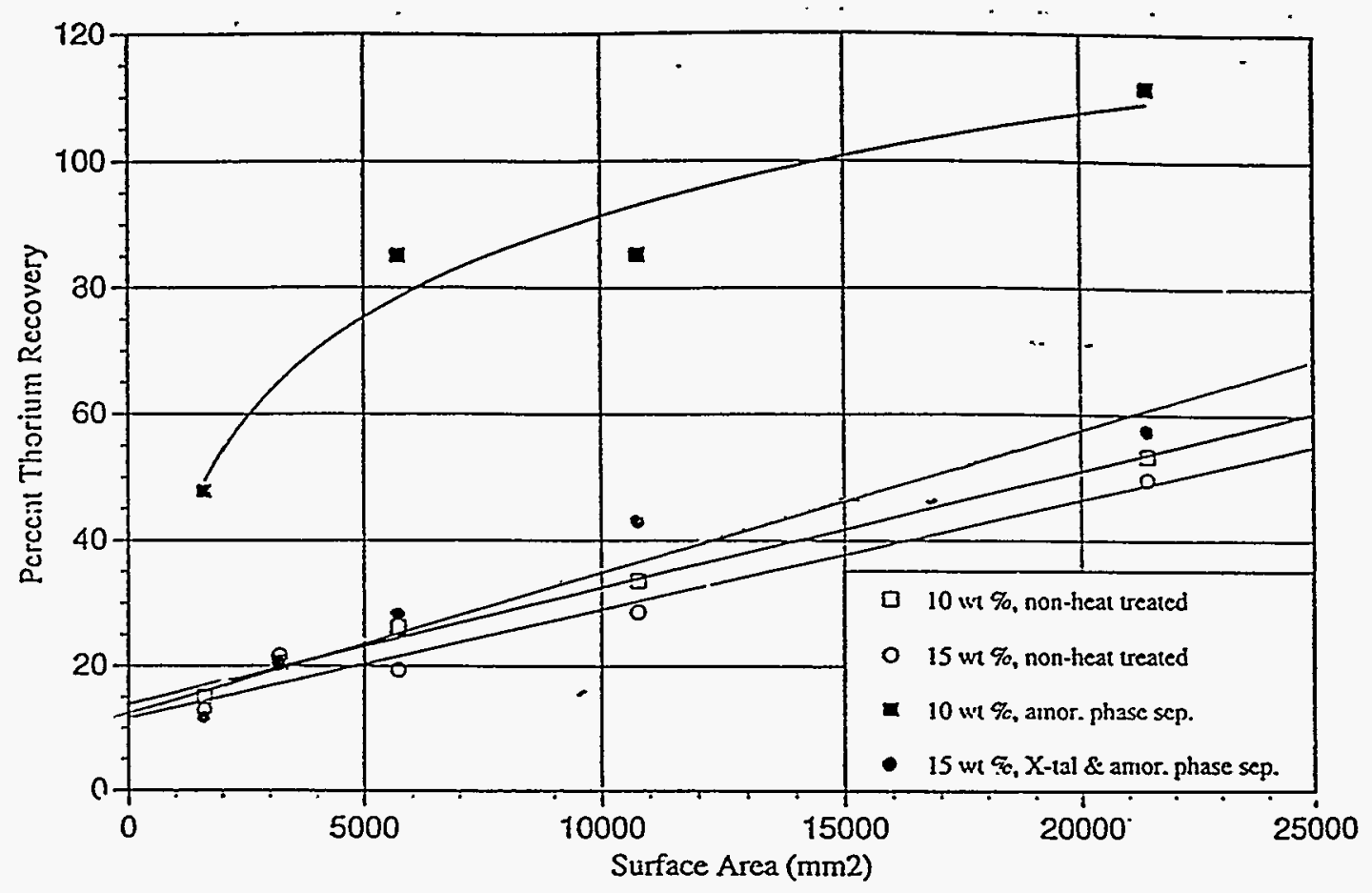

Figure 8. Silicon levels with respect to surface area of heat treated and non-heat treated glasses with 10 and 15 weight percent $\mathrm{ThO}_{2}$ loadings.

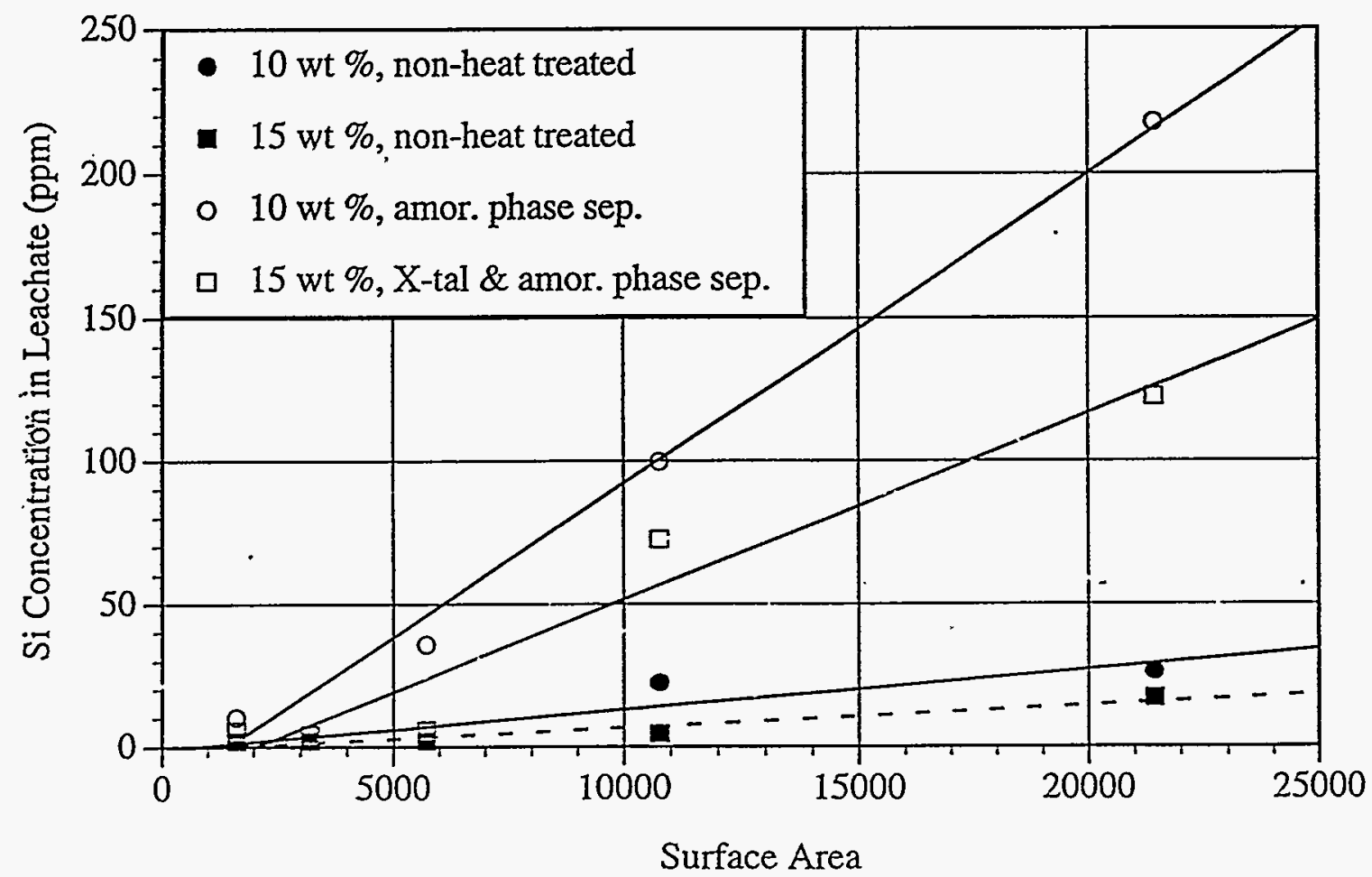


Figure 9 shows Th recovery rates with respect to time of two heat treated glasses with the same temperature and different time and one non-heat treated glass. All glasses had the same ThO2 loading (10 weight percent oxide) and the same composition. The surface area to volume of solids ratio was kept constant. Contact time was varied between 0.25 and 8.0 hours. TEM detected very little crystal formation in either heat treatment, however, the heat treatment of 7 hours had fewer crystals. Over 90 percent of all the Th was recovered from the 40 Mesh size fraction of the 7 hour, $650^{\circ} \mathrm{C}$ heat treatment after four hours. This is considerably better than the 10 hour heat treatment $(\sim 70 \%)$ and significantly better than the non-heat treated sample. The silicon concentration of the same dissolution is depicted in figure 10. All samples contained 2 to $4 \mathrm{ppm}$ silicon in the leachate except the non-heat treated sample aiter 8 hours in $\mathrm{HNO}_{3}(38 \mathrm{ppm})$.

Figure 9. Th recovery rates with respect to time of two differnet heat treatments and one non-heat treated sample.

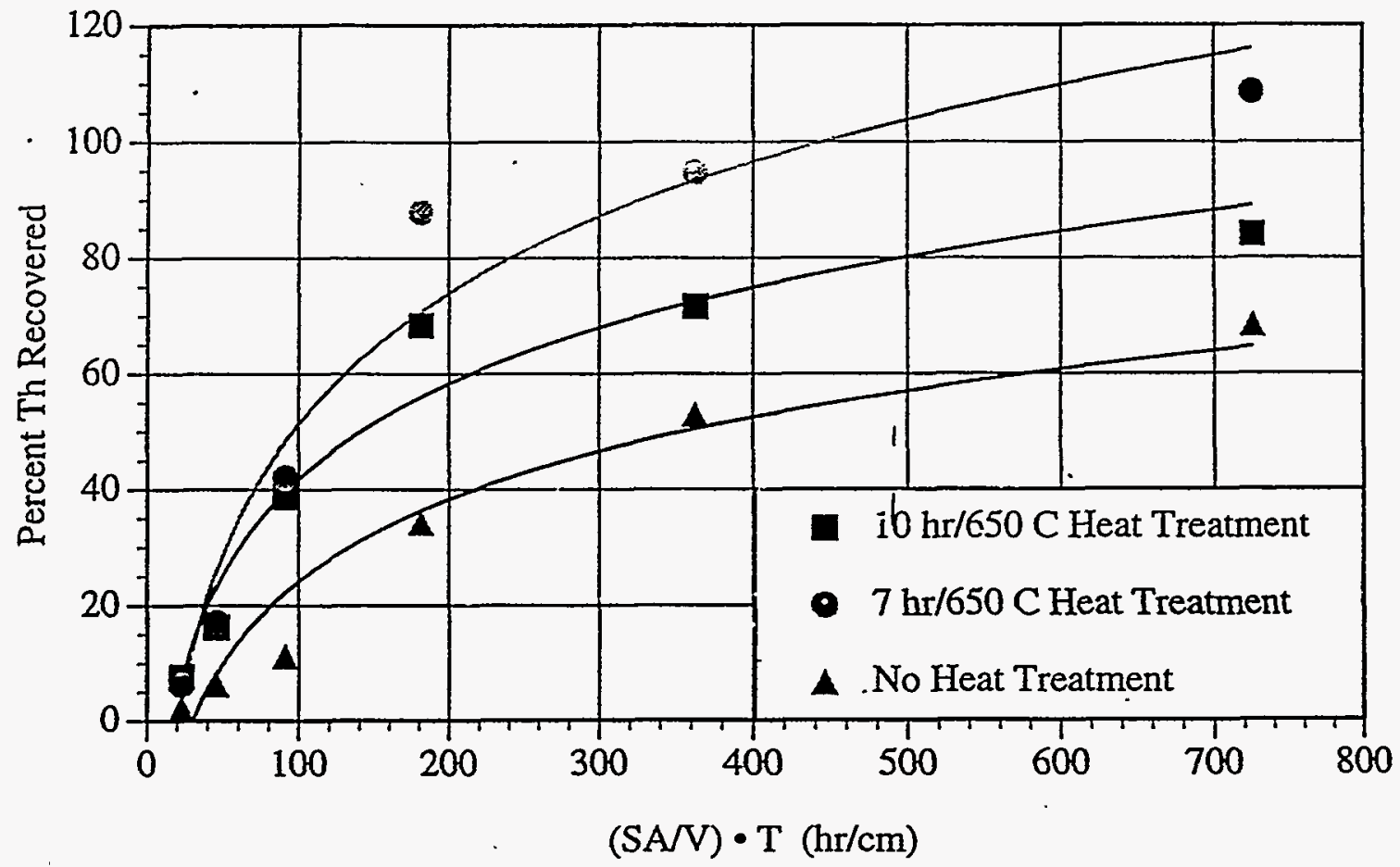


Figure 10. Silicon levels in leachate of 40 mesh size fraction contacted for 0.25 to 8 hours of two different heat treated and one non-heat treated sample.

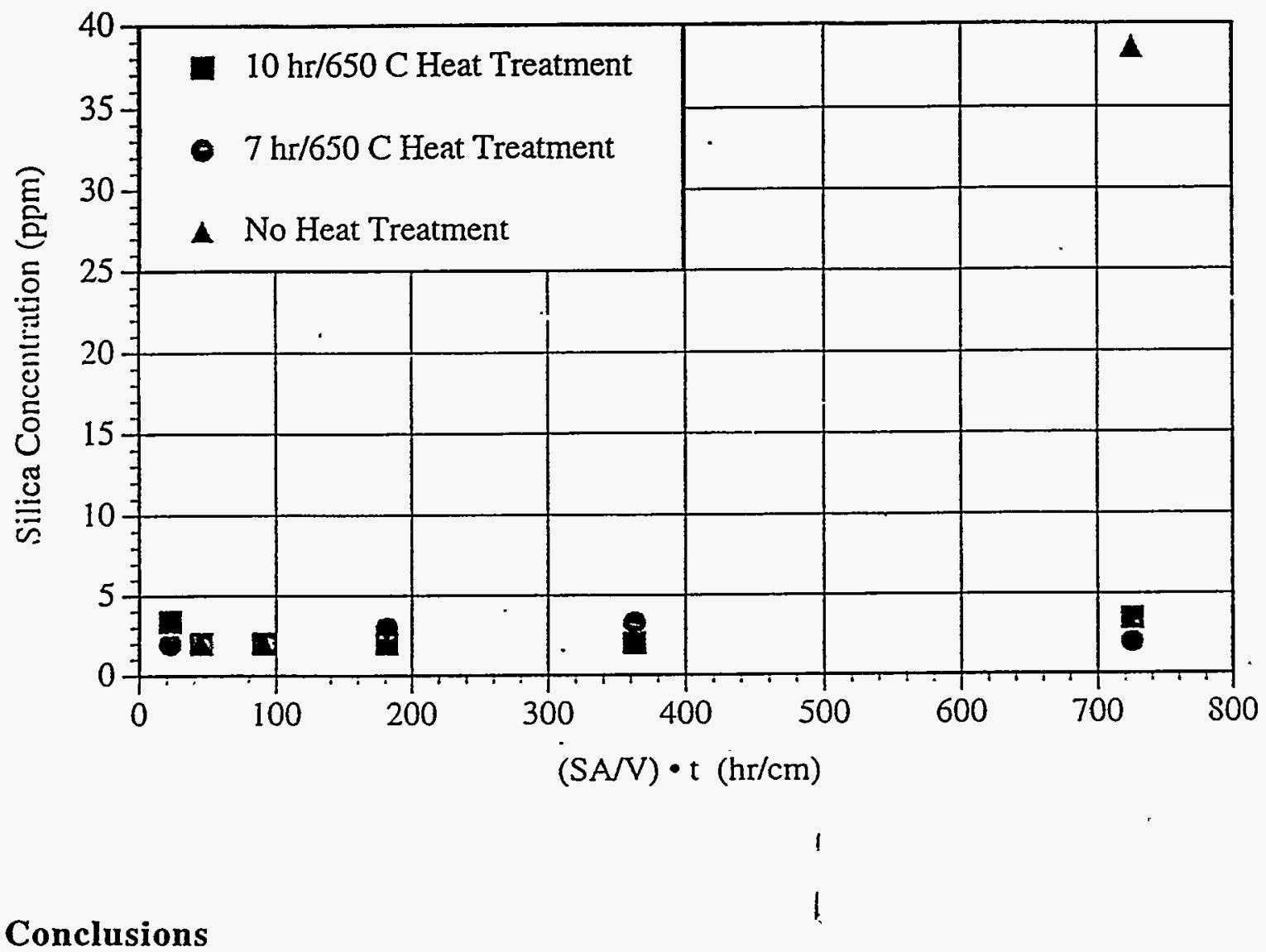

The total amount of crystal formation in a heat treated vycor-type glass can be controlled with time, teniperature and loading. Heat treatments at lower temperatures and for less time inhibit crystal formation while still allowing significant phase separation. If the Thorium loading exceeds 10 weight percent oxide, crystal formation during heat treatment may not be avoided. The total amount of crystal growth has a direct affect on thorium leachability. An increase in crystal formation limits the Th recovery significantly. High thorium loaded glasses (15 weight percent) with heat treatments (increased crystal formation) leach at approximately the same rate as non-heat treated glasses.

A phase separated (amorphous) glass has been produced using thorium as a surrogate for neptunium. Two different homogeneous vycor compositions targeting 10 and 15 weight percent thorium oxide have been processed, heat treated and leached with concentrated nitric acid at $110^{\circ} \mathrm{C}$. Thorium recovery rates have been shown to be considerably better when the glass has been heat treated inducing phase separation that is relatively crystal free. Non-heat treated and crystalline (due to heat treatment) glasses have similar Th recovery rates with respect to surface area. Phase separated amorphous samples were found to have significantly higher thorium concentrations in the leachate compared to non-heat treatcd and crystalline glasses for all mesh sizes. All glasses had increased thorium concentratum in the leachate as surface area increased. 
Thorium leach rates of greater than 90 percent have been achieved by contacting a large mesh size, heat treated glass with nitric acid at $110^{\circ} \mathrm{C}$ for 4 hours. The heat treatment was for 7 hours at $650^{\circ} \mathrm{C}$. The glass contained very few crystals after the heat treatment. Thorium leach rates for a slightly. more crystallized sample was $\sim 20$ percent less. Non-heat treated glasses show $\sim 40$ percent less recovery compared to the sample with very few crystals.

Non-heat trasted glasses exhibited very low silica releases. Typical levels are at or below 5 $\mathrm{ppm}$ of st. 2 dissolved in solution for large mesh sizes and greater than $15 \mathrm{ppm}$ for small mesh six Large glass fragments of phase separated (amorphous) samples had a silica release 1 so below $5 \mathrm{ppm}$. However, glasses containing amorphous phase separation and crystalline phases did show a ten fold (10X) increase in total silica dissolved as the surface area increased.

\section{References}

1. Elmer, T.H., "Porous and Reconstructed Glasses," Engineered Materials Handbook, Volume 4: Ceramics and Glasses (1992).

2. M.H Volf, "Chemical Approach to Glass," pp. 459 - 60, (1984)

3. Pee - D.K. and Hrma, P.R., "Compositional/Durability relationship in Simulated Wa usses," American Chemical Society, I \& EC Division, Emerging Technologies in I . adous Waste Management VII (1995). 